IRA-International Journal of Technology \& Engineering

ISSN 2455-4480; Vol.04, Issue 03 (2016)

Pg. no. 164-171

Institute of Research Advances

http://research-advances.org/index.php/IRAJTE

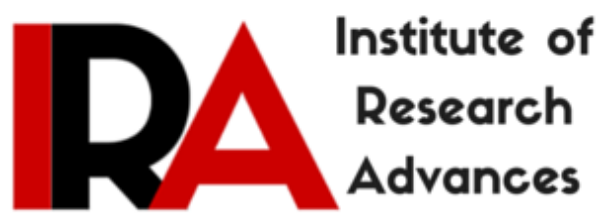

\title{
A study and analysis of wind turbine towers with rotor size at different heights
}

\author{
Dhara P Parikh ${ }^{1}$, Dr. Ashish N Jani ${ }^{2}$ Dr. H. B. Bhadka ${ }^{3}$ \\ ${ }^{1}$ Research Scholar of C. U. Shah University, Wadhwan, Gujarat, India. \\ ${ }^{2}$ Assistant Professor S. K. Patel Institute of Management \& Computer Studies \\ (MCA), Gandhinagar, India. \\ ${ }^{3}$ Dean, Faculty of Computer Science, C. U. Shah University, Gujarat, India.
}

Type of Reviewed: Peer Reviewed.

DOI: http://dx.doi.org/10.21013/jte.v4.n3.p4

\section{How to cite this paper:}

Parikh, D., Jani, A., \& Bhadka, H. (2016). A study and analysis of wind turbine towers with rotor size at different heights. IRA-International Journal of Technology \& Engineering (ISSN 2455-4480), 4(3), 164-171. doi:http://dx.doi.org/10.21013/jte.v4.n3.p4

(C) Institute of Research Advances

(cc)) BY-No

This work is licensed under a Creative Commons Attribution-Non Commercial 4.0 International License subject to proper citation to the publication source of the work.

Disclaimer: The scholarly papers as reviewed and published by the Institute of Research Advances (IRA) are the views and opinions of their respective authors and are not the views or opinions of the IRA. The IRA disclaims of any harm or loss caused due to the published content to any party. 


\section{ABSTRACT}

The aim of this paper is to study and analyse the size of rotor of wind turbine at heights. The study analysis of relevant data at set of for different hub heights of $30 \mathrm{~m}, 40 \mathrm{~m}, 50 \mathrm{~m}, 78 \mathrm{~m}$ and $100 \mathrm{~m}$ is carried out to compute power coefficient and extractable power. An increase in hub height caused an increase in energy generation of $3.52 \%$ and $6.28 \%$ for $78 \mathrm{~m}$ to $100 \mathrm{~m}$, and for $78 \mathrm{~m}$ to $100 \mathrm{~m}$ hub heights, respectively. The results analysis leads to the power attainment in respect of height of hub and rotor size at a particular location of a wind farm. The data analytic finding leads to cost effective design of wind turbine to render required energy at that location of wind turbine.

Keywords: wind turbine, Rotor Size, turbine hub height, wind speed

\section{Introduction}

As per the established fact the adoption of wind energy system to extracts renewable energy is a prime and continued effort in terms of optimum wind energy site selection, size of rotor of a wind turbine and the height of hub etc. - all aimed at extraction of maximum wind energy. Further wind energy is one of the most competitive cost effective options in compression to other renewable resources.

The current trend in the global wind industry is to use taller wind turbine towers to access the stronger and less turbulent wind resources that occur at greater heights. For hub heights of up to $78 \mathrm{~m}$, tubular steel towers have established themselves to be the most cost-effective result. As the tower hub heights increase to 100 and $120 \mathrm{~m}$, however, steel towers start to lose their appeal (Harte \& van Zijl 2007)[1].

As the hub height increases, the towers require being able to withstand increased ultimate loads of wind farm, bending moments and increased fatigue loads and moments. This leads to design and fabrication wind farm tower, nacelle and blade assembly with appropriate material strength. The three most common designs for tall wind turbine towers are:

- $\quad$ The conventional tubular steel tower

- $\quad$ The precast, post-tensioned, segmented concrete tower

- The concrete-steel hybrid tower.

Wind turbine designs are Horizontal Axis Wind Turbine (HAWT) or Vertical Axis Wind Turbine (VAWT). Horizontal Axis Wind Turbines (HAWT) operates converting kinetic energy at wind rotor shaft into electrical energy receiving the parallel wind direction on the turbine rotor. It generates comparatively high energy at high speed winds. The Vertical Axis Wind Turbine (VAWT) turbines have rotational access of rotor standing vertically to the ground and receiving wind from any direction. HAWT depends on rotor radius, incoming wind speed and rotor height position. HAWT can increase affection with laminar wind flow that is less turbulent wind pattern received by wind turbine rotor.

\section{COMPUTATIONAL MODEL}

The following variables are used in mathematical equation forming the parts of mathematical model for computation [2]:

$\mathrm{E}=$ Kinetic Energy $(\mathrm{J}), \rho=$ Density $(\mathrm{kg} / \mathrm{m} 3), \mathrm{m}=$ Mass $(\mathrm{kg}), \mathrm{A}=$ Swept Area $(\mathrm{m} 2)$,

$\mathrm{v}=$ Wind Speed $(\mathrm{m} / \mathrm{s}), \mathrm{Cp}=$ Power Coefficient, $\mathrm{P}=$ Power $(\mathrm{W}), \mathrm{r}=$ Radius $(\mathrm{m}), \mathrm{dm} / \mathrm{dt}=$ Mass flow rate $(\mathrm{kg} / \mathrm{s}), \mathrm{x}=$ distance $(\mathrm{m}), \mathrm{dE} / \mathrm{dt}=$ Energy Flow Rate $(\mathrm{J} / \mathrm{s}), \mathrm{t}=$ time $(\mathrm{s})$ 
The kinetic Energy of an object having mass $\mathrm{m}$ and velocity $\mathrm{v}$ is equal to the work done $\mathrm{W}$ which is done object is displaced to a distance $s$ from rest with constant acceleration under a force $F$ [2].

$\mathrm{E}=\mathrm{W}=\mathrm{Fs}$

The Second Law of Newton's Law states that:

$\mathrm{F}=\mathrm{ma}$

$\mathrm{E}=\operatorname{mas} \ldots(1)$

Using the third equation of indication:

$$
\begin{aligned}
& \mathrm{v} 2=\mathrm{u} 2+2 \mathrm{as} \\
& \mathrm{a}=\frac{\left(v^{2}-u^{2}\right)}{2 s}
\end{aligned}
$$

Initial velocity of the object is zero, i.e. $\mathrm{u}=0$

$$
a=\frac{v^{2}}{2 s}
$$

Substituting it in equation (1), we get that the kinetic energy of a mass in motions is:

$$
E=\frac{1}{2} m v^{2} \ldots(2)
$$

The power in the wind is given by the rate of change of energy [2]:

$$
P=\frac{d E}{d t}=\frac{1}{2} v^{2} \frac{d m}{d t}
$$

As mass flow rate is given by [2]:

$$
\frac{d m}{d t}=\rho A \frac{d x}{d t}
$$

and the rate of change of distance is given by [2]:

$$
\frac{d x}{d t}=v
$$


we get:

$$
\frac{d m}{d t}=\rho A v
$$

Hence, from equation (3), the power can be defined as [2]:

$\mathrm{P}=1 / 2 \rho A v^{3}$

Albert Betz concluded in 1919 that no wind turbine can convert more than 16/27 (59.3\%) of the kinetic Energy of the wind into mechanical energy rotating a rotor. These is known as the Betz Limit or Betz' Law[2]. The hypothetical maximum power efficiency of any design of wind turbine is 0.59 .This is called the "power coefficient" and is defined as [2]:

$$
\mathrm{C}_{\mathrm{pmax}}=0.59
$$

The wind turbines cannot function at this maximum limit. The $\mathrm{Cp}$ value is unique to each turbine type and is a function of wind speed that the turbine is operating in. The various engineering requirements of a wind turbine - strength and toughness in particular - the real world limit is well below the Betz Limit with values of 0.35-0.45 common even in the best designed wind turbines [2]. Hence, the power coefficient needs to be factored in equation (4) and the extractable power from the wind is given by [2]:

$\mathrm{P}_{\text {avail }}=1 / 2 \rho \mathrm{Av}^{3} \mathrm{Cp}$

The swept area of the turbine can be calculated from the length of the turbine blades using the equation for the area of a circle [2]:

$\mathrm{A}=\pi \mathrm{r}^{2}$

Where the radius is equal to the blade length as shown in the figure 1 below [2]:

\section{Figure 1: Rotor Swept Area}

The final calculation that is used to represent the TOTAL power contained in an air stream moving through a certain area. From this there are two very important revelations that can be made:

- $\quad$ Power is connected to the cube of the wind velocity. Thus even small increases in wind velocity result in very significant increases in power.

- $\quad$ Power is connected to the square of the rotor radius. This means that even modest increases in blade length and rotor diameter can make significantly more power available to the turbine - which is precisely why turbines are growing larger and larger in size. 


\section{DATA SOURCE \& ANALYTICS}

Sample computations of the data for set of variables are underneath:

Blade length, $1=70 \mathrm{~m}$

Wind speed, $\mathrm{v}=9.44 \mathrm{~m} / \mathrm{sec}$

Air density, $\rho=1.2354 \mathrm{~kg} / \mathrm{m}^{3}$

Power Coefficient, $\mathrm{Cp}=0.44$

Inserting the value for blade length as the radius of the swept area into equation (8) we have:

$1=r=70 \mathrm{~m}$

$\mathrm{A}=\pi \mathrm{r}^{2}$

$=\Pi * 702$

$=15386 \mathrm{~m}$

We can then calculate the power converted from the wind into rotational energy in the turbine using equation (7):

$\mathrm{P}_{\text {avail }}=1 / 2 \rho \mathrm{Av}^{3} \mathrm{Cp}$

$=1 / 2 \times 1.23 \times 15386 \times 9.443 \times 0.44$

$=3500000 \mathrm{kWh}$

The secondary data is obtained data of nominal power, rotor height, hub height; annual energy yield is tabulated undertaken (Table: 1$)$.

Table: 1 Obtained data of nominal power, rotor height, hub height, annual energy

The analytic from table reveals that the annual energy yield gives increasing power from hub height and its corresponding rotor height $46 \mathrm{~m}$ to $115 \mathrm{~m}$ to the acceptable implementation level shows in figure 2,3 which is experiment in $\mathrm{R}$ statistical computing 3.1.1 version.

Figure 2: Wind data based on hub height, rotor height and wind speed

Figure 3: Obtained data of nominal power, wind speed, rotor height, hub height, annual energy 


\section{Conclusion}

The computations on the data and analytics of the sweptback design supports to ensure the wind turbine system higher level of efficiency possible. The research track have strongly indicated that The wind turbines designed and developed currently with upcoming materials and technologies have achieved much higher efficiency than their predecessors, mainly due to the advancement in stated technologies.

\section{References}

1. A C Way, G P A G van Zijl, "A study on the design and material costs of tall wind turbine towers in South Africa" Journal of the South African Institution of Civil Engineering Vol 57 No 4, December 2015, Pages 45-54, Paper 1231

2. Wind Turbine Power Calculations RWE npower renewables Mechanical and Electrical Engineering Power Industry 
(Tables \& Figures)

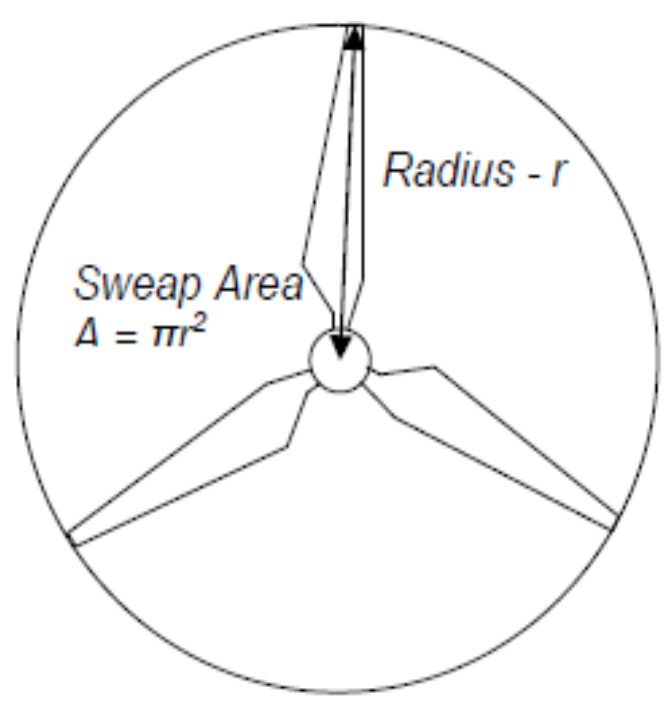

Figure 1: Rotor Swept Area

\begin{tabular}{|l|l|l|l|l|l|}
\hline \multicolumn{7}{|c|}{ Wind data and hub heights selected for the study. } \\
\hline Nominal Power $(\mathrm{kW})$ & 30 & 80 & 250 & 600 & 1500 \\
\hline Rotor height $(\mathrm{m})$ & 15 & 20 & 30 & 46 & 70 \\
\hline Hub height $(\mathrm{m})$ & 30 & 40 & 50 & 78 & 100 \\
\hline Wind speed (m/sec) & 5.68 & 6.54 & 8.05 & 8.86 & 9.44 \\
\hline $\begin{array}{l}\text { Avg. Annual energy yield } \\
(\mathrm{kWh})\end{array}$ & 35,000 & 95,000 & 400000 & 1250000 & 3500000 \\
\hline
\end{tabular}

Table: 1 Obtained data of nominal power, rotor height, hub height, annual energy 


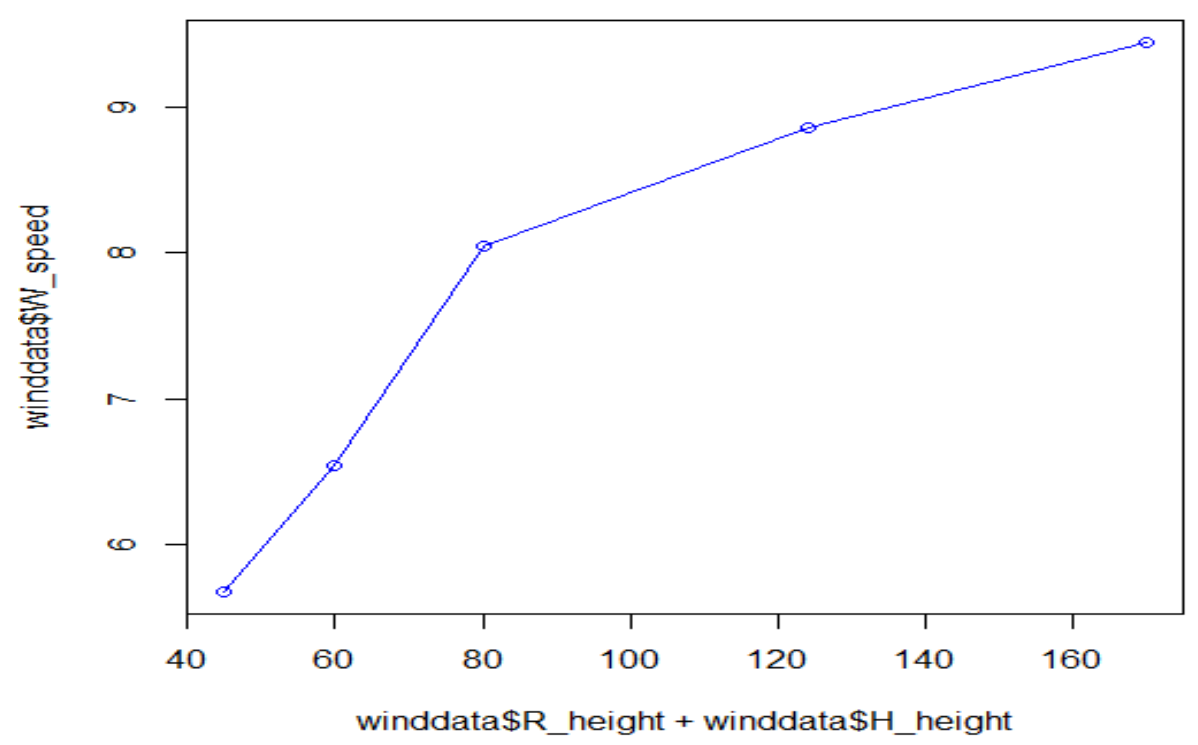

Figure 2: Wind data based on hub height, rotor height and wind speed

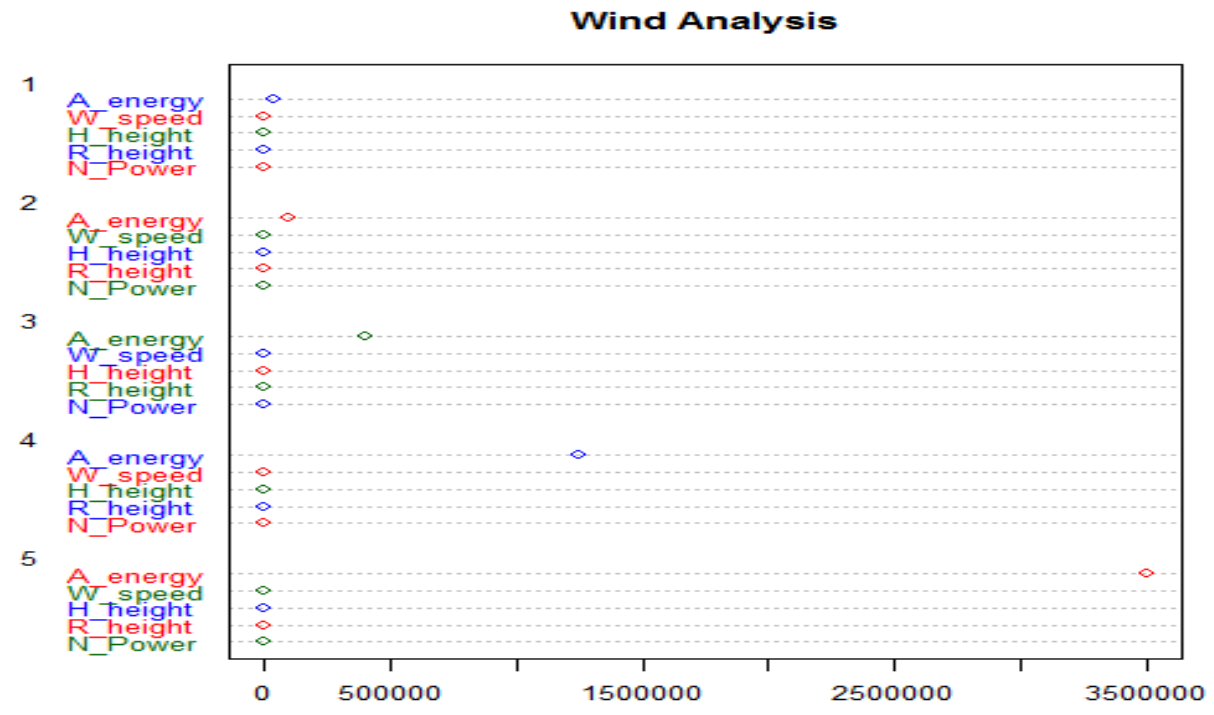

Figure 3: Obtained data of nominal power, wind speed, rotor height, hub height, annual energy 